\section{Troubled waters}

The North Sea: Challenge and Opportunity. (Report produced by Study Group of David Davies Memorial Institute of International Studies.) Pp. xiii + 324. (Europa: L o n d o n, 1975.) £6.95; $\$ 21.00$.

SinCE the discovery of hydrocarbons at exploitable depths in the British sector of the North Sea, public policy towards the area has been dominated by considerations of energy and little else. On land, considerations of ecology and the environment have acquired sufficient political force for the formation of a single Department of the Environment. The concept of land-use planning has become part of the vocabulary of bureaucrats, politicians, and the media elite. The same cannot, alas, be said for the sea, especially for the North Sea.

Although voices have been raisedon the National Environmental $\mathrm{Re}$ search Council (NERC), in the recent Fabian Tract on Sea Use Planning, at the various conferences organised by the Greenwich Forum, and in various submissions to parliamentary committees-little has changed. To quote from the above report:

“. . different activities in the North Sea are regulated at different levels and with varying degrees of thoroughness.

It is only where a problem or situation has been seen as critical that measures have been taken to try to meet it. Otherwise inertia and the usual shortterm view that characterises most politics prevails. Machinery is thus lacking for considering, evaluating and regulating for the long-term the complex of interrelated activities (which actually take place in the North Sea) .... and this lack must be attributed to the absence of a general awareness of the need for such an integrated approach".

The report comments on the existence of a "widespread, if rather unfocused, realisation that there is a need for overall environmental planning. The danger, as always, is that lip service to an idea may become a substitute for hard thinking and eventual action; and this can postpone the recognition of the immediacy and gravity of the problem."

One of the most serious obstacles to such recognition in the past has been that those who recognise the "immediacy and gravity of the problem" in their own field are either scientists or technologists, lacking either the political understanding or the grasp of international issues necessary to convey their sense of urgency across those barriers to understanding or communication which divide the bulk of politicians, civil servants and leaders of opinion from the research laboratories, common rooms, technological seminars and institutes of engineering. The civil servant or politician, however, has as much trouble bringing home to the numerate the compulsions of international law, the resistance of vested interests, the difficulties of reaching a democratic consensus, and the nature of political realities.

One of the many merits of this study group is that it effectively married expertise in environmental science and in international law. The chapters on the international and national aspects of the present legal regime in the North Sea should be essential reading for all concerned with the scientific and technological sides of the exploration, exploitation and development of the resources of the North Sea. Equally compulsory reading for all specialists should be the chapter on the competing uses and interests in the North Sea.

The report points to various obvious lacunae in our understanding of the North Sea: water budget; history of sedimentation; sea-air interaction; food chains; and basic chemical information on estuaries. To control man-made changes in the ecology of the North Sea very much more research needs to

\section{Student physics}

Introduction to Modern Theoretical Physics. by Edward G. Harris. Vol. 1: Classical Physics and Relativity. Pp. xvii $+383+9$. Vol. 2: Quantum Theory and Statistical Physics. Pp. xvii + 385-780+9. (Wiley-Interscience: New York and London, December 1975.) £13.50; \$27.00 each volume.

PROFESSOR HARRIS remarks that the tendency to specialise has increased to such an extent that large gaps occur in the education of $\mathrm{PhD}$ candidates in physics. He has attempted to write a texthook which covers everything such a student should know. The course covers mechanics, continuum mechanics, electromagnetism, relativity, general relativity, quantum mechanics, quantum field theory, elementary particles, thermodynamics, statistical mechanics and plasma physics.

The section on continuum mechanics is extremely short, whereas the treatment of general relativity is too ambitious (it includes attempts at unified field theory and geometrodynamics). The treatment of experimental questions in general relativity reflects the author's own enthusiasm. and in most subjects there is a balanced choice of topics. The author even has time for a few historical remarks. Much of the book overlaps, intentionally, with undergraduate be undertaken.

Its recommendations on the political level are, to my knowledge, streets ahead of the thinking of any government policymaking body in Western Europe, calling at the national level for a considerable reorganisation of national administration, involving the establishment of a UK Cabinet Committee with responsibility for interdepartmental collaboration and of a permanent parliamentary committee on the marine environment; and on the international level for the establishment of a regional regime for the North Sea in the form of a Standing Conference of North Sea States with an international economic committee and a joint North Sea policing service. It will alas be some time before these become politically feasible. What we need now is a survey of the policies of the other North Sea states to match that dealing with Britain.

This book cannot be too strongly recommended, at a time when so much of Britain's future depends on the way in which the opportunities provided by the recent discoveries in the North Sea are realised.

D. C. Watt

topics, even down to some things covered in the first year.

Although the intentions of the book are good, I doubt that it will ever become the English Handbuch der Physik. The section on classical mechanics is less good than $\mathrm{H}$. Goldstein's book; the quantum mechanics section would not be preferred to Dicke and Wittke; and so oneach topic is already well covered by existing texts at the same level.

The use of imaginary time $x_{4}=i c t$ instead of the usual $x_{1}=c t$, leads to confusion between hyperbolic and elliptic equations. The author is overcautious in condemning the KleinGordon equation as having "unsatisfactory features". The treatment of boundary conditions on the Schrodinger wave function is left vague with the statement that $\psi$ should be "wellbehaved". Understanding this point is not helped by his advocacy of the Dirac bra and ket formalism. A simple explanation is found in Kemble's book-one requires selfadioint boundary conditions. The author is also clearly out of his depth (p. 400) when mentioning unbounded operators. I would have preferred the theory of the Dirac sea to have been left unsaid; its inconsistencies were bypassed by second quantisation 45 years ago.

Nevertheless, a physicist who knows everything in these books will be widely educated in modern theoretical physics.

R. F. Streater 